Quim. Nova, Vol. 25, No. 3, 412-419, 2002.

\title{
SISTEMAS INTERFACEADOS DE ANÁLISE POR INJEÇÃO EM FLUXO E ELETROFORESE CAPILAR (FIA - CE): DESAFIOS, APLICAÇÕES E PERSPECTIVAS
}

\author{
Carlos E. S. Miranda* e Emanuel Carrilho \\ Instituto de Química de São Carlos, Universidade de São Paulo, CP 780, 13566-590 São Carlos - SP \\ Ana Paula Gervasio e Maria Fernanda Giné \\ Centro de Energia Nuclear na Agricultura, Universidade de São Paulo, CP 96, 13400-970 Piracicaba - SP
}

Recebido em 6/4/01; aceito em 30/8/01

\begin{abstract}
FLOW INJECTION ANALYSIS - CAPILLARY ELECTROPHORESIS HYPHENATED SYSTEMS (FIA-CE): CHALLENGES, APPLICATIONS AND PERSPECTIVES. A review about the state-of-the-art of flow injection analysis (FIA) - capillary electrophoresis (CE) systems is presented. The basic principles of flow injection and capillary electrophoresis are briefly revised. The main aspects of the FIA-CE hybridization, including advantages and shortcomings, are discussed. Some applications involving all different designs are also presented. This review covers the literature from 1997 up to 2000.
\end{abstract}

Keywords: flow injection analysis; capillary electrophoresis; instrumentation.

\section{INTRODUÇÃO}

A análise por injeção em fluxo (FIA) ${ }^{\text {a, } 1}$, proposta na metade dos anos 70, representou um avanço significativo no campo da automatização em química analítica. Esse processo consolidou-se de tal forma que mais de 8000 artigos já foram publicados, envolvendo as áreas industrial, agronômica, clínica e ambiental, entre outras.

A eletroforese capilar $(\mathrm{CE})^{\mathrm{b}}$ teve como contribuições pioneiras os trabalhos de Mikkers et al. ${ }^{2}$ em 1979 e Jorgenson e Lukacs ${ }^{3}$ em 1981. Desde então, tem expandido-se continuamente, inicialmente, no campo da bioquímica e, posteriormente, da química analítica. No começo da década de noventa, ocorreu um aumento significativo do número de publicações em eletroforese capilar, sendo que até 2000, cerca de 12000 artigos já haviam sido publicados. O princípio básico da eletroforese é a separação de espécies eletricamente carregadas a partir de suas diferentes mobilidades eletroforéticas devido à ação de um campo elétrico ${ }^{4}$.

Embora seja uma técnica bastante versátil, a qual é empregada na separação de uma grande variedade de espécies químicas, de íons inorgânicos simples até moléculas de alto peso molecular, a eletroforese requer que certos tipos de amostras passem por etapas de prétratamento antes de serem introduzidas no sistema eletroforético. Entre essas etapas encontram-se: a extração, a filtração, a centrifugação e a diluição, as quais, não sendo realizadas em linha, levam a um aumento do tempo de análise, a um aumento dos riscos de contaminação das amostras, à perda de precisão das medidas, à perda de analitos e à manipulação indesejável de reagentes e solventes tóxicos. A análise por injeção em fluxo, por sua vez, é um processo muito eficiente no que se refere à combinação entre pré-tratamento e introdução de amostras em linha em separações não cromatográficas com múltiplos sistemas de detecção. Estes, em certos casos, têm o seu desempenho melhorado pela associação com os sistemas FIA. Entre os detectores empregados na injeção em fluxo encontram-se

\footnotetext{
*e-mail: cmiranda@cena.usp.br

${ }^{a}$ Do inglês: Flow Injection Analysis

${ }^{\mathrm{b}}$ Do inglês: Capillary Electrophoresis
}

os espectrométricos e os eletroquímicos ${ }^{5}$. Nesse sentido, a associação entre a eletroforese e a análise em fluxo seria bastante vantajosa, uma vez que a forma de introdução da amostra e a baixa sensibilidade estão entre as principais desvantagens da eletroforese capilar.

Nesta revisão, é apresentado o estado-da-arte dos sistemas FIA$\mathrm{CE}$, incluindo as principais contribuições feitas aos sistemas pioneiros, os novos sistemas propostos, além de algumas aplicações. Foram enfatizados os aspectos relacionados às implicações do acoplamento FIA-CE, à automatização e à miniaturização dos sistemas. A revisão abrange o período compreendido entre 1997 e 2000.

\section{A análise por injeção em fluxo (FIA)}

O princípio da Análise por Injeção em Fluxo é muito simples e baseia-se na inserção de uma alíquota da solução da amostra, a qual sofre dispersão ao ser conduzida através do percurso analítico por uma solução transportadora, que pode ser o próprio reagente, até o detector. Em um artigo publicado em 1989, os conceitos básicos desse processo foram didaticamente discutidos ${ }^{6}$.

O processo analítico divide-se, basicamente, em três estágios: pré-tratamento das amostras, determinação dos analitos e processamento e análise dos dados. O primeiro estágio envolve etapas críticas como: amostragem e preservação da amostra, dissolução, separação/pré-concentração, reações químicas e transporte até o detector, as quais irão definir a exatidão e a precisão dos resultados. É justamente nesse estágio que a versatilidade da injeção em fluxo foi, desde cedo, reconhecida, uma vez que tornava possível a execução, em linha, dessas operações, as quais eram, normalmente, realizadas em batelada. Assim, ocorreu uma crescente associação da análise por injeção em fluxo (FIA) ${ }^{7-9}$ com outras técnicas pelas razões amplamente discutidas na literatura ${ }^{10,11}$. Entre essas razões, a facilidade de automatização inerente à própria concepção do processo, reforçou a versatilidade que é atribuída à análise por injeção em fluxo. Entre as vantagens características da injeção em fluxo estão também: a economia de reagentes, a minimização de contaminações, a alta frequiência analítica e a facilidade de associação com vários tipos de detectores. Visando melhorar o desempenho dos sistemas FIA, uma série de alterações do conceito original foram propostas, tais como: melhor homogeneização entre amostra e reagente utilizando a adi- 
ção de reagentes por confluência ${ }^{12}$, economia de reagentes utilizando os processos de zonas coalescentes ${ }^{13}$ e fluxo intermitente ${ }^{14}$, ou ainda diluição em linha da solução da amostra para que a concentração da mesma se situasse na faixa de operação ótima do instrumento utilizando o processo de reamostragem ${ }^{15}$.

\section{A eletroforese capilar (CE)}

Eletroforese é o deslocamento de partículas ou moléculas ionizadas sob o efeito de um campo elétrico em um meio condutor líquido, geralmente, aquoso. Um sistema básico de eletroforese consiste de dois reservatórios que contêm uma solução tampão idêntica e que são conectados entre si por meio de um tubo capilar de sílica fundida, preenchido com a mesma solução tampão, a qual é denominada eletrólito. Em cada reservatório é mantido um eletrodo de platina que o conecta a uma fonte de alta tensão que fornece a diferença de potencial requerida para a separação dos analitos. A mobilidade eletroforética, responsável pela migração dos íons, é determinada pelas razões carga/raio hidratado, isto é, os íons menores migram mais rapidamente que íons maiores de mesma carga. Se os íons apresentam o mesmo tamanho, o de maior carga migra mais rápido que o íon de menor carga ${ }^{4}$. Em 1996, foi publicado um artigo, no qual foram detalhadamente apresentados os conceitos básicos e os fundamentos da eletroforese capilar ${ }^{16}$.

Assim como o processo FIA, a Eletroforese Capilar (CE) também foi associada a várias técnicas de detecção, dentre as quais destacam-se: absorbância UV-vis, fluorescência, fluorescência induzida a laser, amperometria e espectrometria de massas. Há, entretanto, um predomínio dos detectores de absorbância UV-vis em eletroforese capilar. Essa técnica é caracterizada pela alta eficiência de separação que é assegurada pelos capilares de diâmetro reduzido, os quais permitem uma melhor dissipação do calor gerado. Caso não houvesse a dissipação do calor, o aumento da temperatura poderia levar ao alargamento da zona da amostra, decomposição da amostra ou ebulição do eletrólito. Desde que o calor gerado seja dissipado, é possível empregar diferenças de potencial mais altas que asseguram uma melhor eficiência de separação. Os tempos de separação alcançados em eletroforese são dependentes das diferenças de potencial aplicadas e do comprimento dos capilares. Potenciais mais altos e capilares de menor comprimento garantem tempos de separação mais curtos. Os volumes de amostra utilizados em CE são muito pequenos, da ordem de nanolitros ${ }^{17}$. Isso representa uma grande vantagem no caso de não haver disponibilidade de um grande volume de amostra, como no caso de amostras forenses ou biológicas ${ }^{18}$. A quantidade de reagentes utilizados em CE também é muito pequena. É possível utilizar um volume da ordem de microlitros durante um dia inteiro de análises. Como existem diferentes tipos de eletroforese, é possível analisar, com a mesma eficiência, uma gama de amostras, sejam elas moléculas simples ou macromoléculas, polares ou não polares e iônicas ou neutras. Dentre as modalidades de eletroforese capilar encontram-se: a eletroforese capilar de zona $\left(\mathrm{CZE}^{\mathrm{a}}\right)$ ou, simplesmente, eletroforese capilar, a cromatografia eletrocinética micelar $\left(\mathrm{MEKC}^{\mathrm{b}}\right)$, a eletroforese capilar em gel $\left(\mathrm{CGE}^{\mathrm{c}}\right)$, a eletroforese capilar de focalização isoelétrica $\left(\mathrm{CIEF}^{\mathrm{d}}\right)$ e a isotacoforese capilar $\left(\mathrm{CITP}^{\mathrm{e}}\right)$. A disponibilidade dessas diferentes modalidades contribuiu,

\footnotetext{
${ }^{a}$ Do inglês: capillary zone electrophoresis

${ }^{\mathrm{b}}$ Do inglês: micellar electrokinetic chromatography

${ }^{\mathrm{c}}$ Do inglês: capillary gel electrophoresis

${ }^{d}$ Do inglês: capillary isoelectric focusing

${ }^{\mathrm{e}}$ Do inglês: capillary isotachophoresis
}

de forma significativa, para consolidar a versatilidade atribuída à eletroforese capilar ${ }^{4}$.

\section{Considerações gerais sobre o acoplamento FIA-CE}

Exatidão, precisão e economia de reagentes são características normalmente associadas aos sistemas FIA. Isso deve-se ao fato dos sistemas utilizados serem fechados, o que minimiza a contaminação e o desperdício de amostras e reagentes. Como os procedimentos são implementados em linha nos sistemas de análise em fluxo, estes são também caracterizados pelas altas freqüências analíticas. Portanto, quando é necessário fazer pré-tratamento das amostras, o emprego dos sistemas FIA é bastante vantajoso, uma vez que tornam possível a implementação de procedimentos como diluição, pré-concentração ou digestão das amostras em linha. Dever ser salientado ainda, como já discutido anteriormente, que os sistemas FIA podem ser utilizados com diferentes detectores, tais como: espectrométrico, fluorimétrico, luminescente, eletroquímico, dentre outros ${ }^{5}$.

A análise em fluxo é um processo caracterizado pela introdução e pré-tratamento de amostras em linha, de forma que o acoplamento FIA-CE seria bastante vantajoso para superar certas limitações da eletroforese capilar. Entre essas limitações encontra-se a baixa sensibilidade que, no caso da detecção espectrofotométrica em coluna capilar, deve-se ao caminho ótico reduzido. Esse problema poderia, por exemplo, ser compensado incluindo-se uma coluna com fase sólida no módulo de análise do sistema FIA para pré-concentração dos analitos.

A precisão dos resultados e a frequiência analítica nos sistemas CE convencionais são prejudicadas devido à forma de introdução da amostra, seja eletrocinética ou hidrodinâmica, a qual é discreta. Ao empregar o sistema FIA, as soluções das amostras podem ser introduzidas em linha, garantindo a precisão das medidas e a alta frequiência analítica, já que as operações são contínuas. No caso da injeção eletrocinética, há ainda uma seleção discriminatória das espécies, ou seja, aquelas com maior mobilidade eletroforética são preferencialmente introduzidas no capilar.

Um outro aspecto a ser considerado nos sistemas CE refere-se ao tipo de matriz a ser analisada. No caso de amostras que contêm uma grande quantidade de proteínas ou de macromoléculas, é necessário fazer um pré-tratamento para evitar que os componentes da amostra sejam adsorvidos nas paredes do capilar. Esse pré-tratamento pode ser convenientemente feito em linha empregando os sistemas FIA. É preciso considerar ainda que, nos sistema de análise em fluxo, o volume de amostra utilizado é da ordem de $\mathrm{mL}$, enquanto que, em CE, é da ordem de nL. Desse modo, é preciso estabelecer um compromisso para que o baixo consumo de amostra, característico dos sistemas CE, seja mantido.

Por fim, uma vez que grandes diferenças de potencial são utilizadas nos sistemas FIA-CE, é necessário que a fonte de alta tensão seja física e eletricamente isolada do sistema FIA por razões de segurança.

\section{SISTEMAS FIA-CE}

Em 1997, independente e simultaneamente, Kuban et al. ${ }^{18}$ e Fang et al. ${ }^{19}$ desenvolveram as interfaces pioneiras que permitiram o acoplamento FIA-CE. As interfaces são bastante similares em seu princípio de funcionamento e esses pesquisadores têm publicado uma série de artigos relatando as aplicações das mesmas em amostras reais. A interface desenvolvida por Kuban et al. ${ }^{18}$ foi construída em Plexiglas ${ }^{\circledR}$ e consistia de um canal horizontal através do qual a solução da amostra era transportada pela solução tampão a partir do sistema FIA. O capilar eletroforético foi inserido em um tubo de 
politetrafluoretileno (PTFE) para facilitar a troca de capilar e esse conjunto foi fixado perpendicularmente ao canal, empregando-se um anel de borracha e um conector de polietileno, conforme mostra a Figura 1. Um eletrodo de platina foi fixado na outra extremidade da câmara também na posição perpendicular para fechar o circuito elétrico. A câmara foi conectada ao sistema FIA por meio de um tubo de polietileno de $5 \mathrm{~cm}$ de comprimento. A alíquota de solução da amostra era transportada pela solução eletrolítica até a câmara e, ao passar pela extremidade do capilar, era eletrocineticamente introduzida em seu interior. O excesso era descartado através de um canal localizado na parte superior da câmara.

A interface proposta por Fang et al. ${ }^{19}$ é apresentada na Figura 2. Essa interface consistia de um recipiente cônico aberto, o qual foi fixado verticalmente no fundo de um reservatório de plástico. A solução tampão era introduzida pela parte inferior do cone e forçada a sair por uma abertura localizada na parte superior do reservatório de entrada. Posteriormente, esse reservatório foi eliminado, sendo o capilar e o eletrodo mergulhados diretamente no cone ${ }^{20}$. O nível de líquido desse reservatório era mantido constante porque a vazão do fluxo de saída era maior que a vazão do fluxo de entrada. Isso permitia que o reservatório de entrada mantivesse o mesmo nível de líqui-

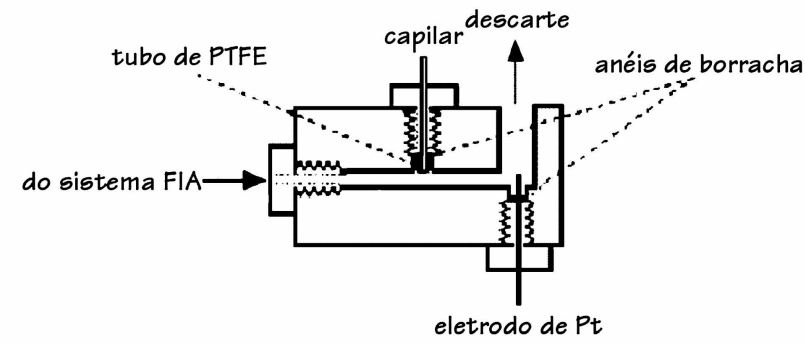

Figura 1. Diagrama esquemático da primeira interface desenvolvida para FIA-CE com amostragem perpendicular à direção do fluxo. Reproduzido da Anal. Chim. Acta 337, Kuban, P.; Engstrom, A.; Olsson, J.C.; Thorsen, G.; Tryzell, R.; Karlberg, B.; New interface for coupling flow-injection and capillary electrophoresis, 117-124, 1997, com a permissão da Elsevier Science

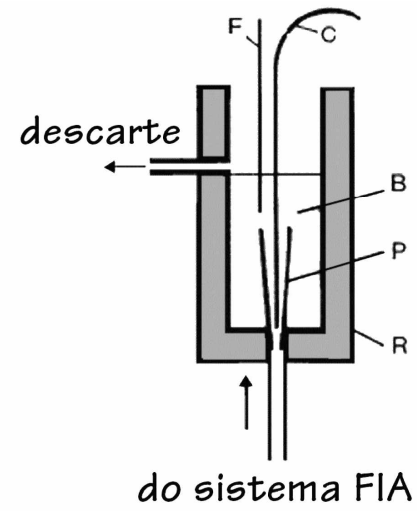

Figura 2. Diagrama esquemático da interface FIA-CE com reservatório de fluxo e amostragem frontal. $R$ - reservatório de plástico, $E$-eletrodo de platina, $C$ - coluna capilar, $P$ - ponta de uma pipeta cônica, $B$ - solução do eletrólito e do descarte. Reproduzido da Anal. Chim. Acta 346; Fang, Z.-L.; Liu, Z.-S.; Shen, Q.; Combination of flow injection with capillary electrophoresis. Part I. The basic system; 135-143; 1997, com a permissão da Elsevier Science do do reservatório de saída reduzindo, desse modo, o fluxo hidrodinâmico no capilar a um mínimo. O capilar foi introduzido no interior do cone até próximo ao orifício de entrada, enquanto o eletrodo foi mergulhado no reservatório de entrada. A alíquota da solução da amostra era transportada pela solução eletrolítica até o reservatório, onde uma parte era introduzida no capilar por eletroosmose e a outra passava para o reservatório sendo o excesso descartado.

As principais diferenças entre as duas câmaras referem-se à direção do fluxo do eletrólito em relação ao capilar e ao eletrodo e ao modo como o nível hidrostático é mantido constante nas celas. Nas duas interfaces foi possível realizar uma série de injeções eletrocinéticas das soluções das amostras sem interrupção da ddp aplicada e sem a necessidade de transferir o capilar do reservatório da amostra para o reservatório do tampão e vice-versa. De acordo com as observações de Kuban et al. ${ }^{18}$, no acoplamento FIA-CE, a vazão, a ddp aplicada e o volume de amostra injetado devem apresentar valores tão grandes quanto possível. Por outro lado, o comprimento e o diâmetro interno do tubo de PTFE que conecta o sistema FIA à interface devem ser tão pequenos quanto possível. Como principal desvantagem do sistema proposto foi apontada a forma de introdução da amostra, a qual era obrigatoriamente eletrocinética. No caso do sistema FIA-CE proposto por Fang et al. ${ }^{19}$, os autores consideraram que a diminuição do volume de amostra injetado e o aumento da vazão do fluxo transportador causaram aumento da eficiência de separação mas, com perda de sensibilidade. Como desvantagens foram apontadas o consumo de amostra, da ordem de microlitros, e o efeito discriminatório provocado pela injeção eletrocinética. Ambos os grupos ressaltaram que as potencialidades do acoplamento FIA-CE residiam na possibilidade de implementar em linha processos como diálise, difusão gasosa, pré-concentração e separação, ou ainda, quaisquer pré-tratamentos da amostra que fossem requeridos.

Conforme já discutido, o efeito discriminatório, causado pela injeção eletrocinética, foi apontado como principal limitação tanto no sistema proposto por Kuban et al. ${ }^{18}$ como naquele proposto por Fang et al. ${ }^{19}$. Em 1999, Kuban et al. ${ }^{21}$ desenvolveram uma interface baseada na injeção hidrodinâmica para eliminar o efeito discriminatório da interface com divisão de fluxo. Esse sistema consistia de duas bombas peristálticas, de uma válvula de injeção, da interface, da fonte de alta voltagem e de uma válvula eletromagnética. Esta válvula era utilizada para abrir e fechar o canal de saída da interface FIA-CE e era acionada por meio de um circuito eletrônico que consistia de uma fonte com potência de $24 \mathrm{~V}$ e de um relê de tempo programável. Um segundo relê foi utilizado para interromper o fornecimento da ddp durante a etapa de injeção. Quando uma alíquota da solução da amostra era introduzida no percurso analítico e transportada pelo eletrólito até o capilar, a contagem de tempo no primeiro relê era iniciada. Quando a alíquota de amostra alcançava o capilar, a válvula eletromagnética fechava a saída da câmara por um intervalo de tempo de 0,1 a $1 \mathrm{~s}$. Neste intervalo, a fonte de alta voltagem era desligada e uma pequena fração da amostra era hidrodinamicamente injetada no capilar. Em seguida, a fonte de alta voltagem era novamente acionada e a separação dos constituintes, iniciada. $\mathrm{O}$ número total de injeções em uma corrida eletroforética dependia do tempo necessário para o aparecimento do pico correspondente à primeira injeção. Segundo os autores, o emprego da injeção hidrodinâmica, a qual é livre do efeito discriminatório, permite que sejam feitas análises quantitativas, a partir da construção de curvas analíticas com relações lineares para subseqüente determinação de concentrações desconhecidas de amostras. Os autores também salientaram que esse modo de injeção é independente das diferenças de condutividade das amostras e que nem a adição padrão nem a correção de condutividade eram necessárias. 
Nesse mesmo ano, Pu e Fang ${ }^{22}$ propuseram uma interface com divisão de fluxo sem o efeito discriminatório com a injeção da amostra baseada no fluxo eletroosmótico. O dispositivo para injeção da amostra pelo fluxo eletroosmótico é apresentado na Figura 3 e foi construído empregando-se uma junção de Nafion ${ }^{\circledR}$ de 6 mm de comprimento, a qual foi utilizada para recobrir uma secção do capilar. Nessa região, foi aplicada uma leve pressão para fraturar o capilar, o qual foi fixado em uma lâmina de vidro com cola à base de epóxido de ambos os lados da junção a $3 \mathrm{~mm}$ da extremidade do tubo de Nafion. Após a secagem da cola, as duas extremidades da junção de Nafion e a parte recoberta com a cola foram envolvidos com um elastômero de silicone adesivo, deixando descoberta apenas a secção central do tubo de Nafion, onde situava-se a fratura. A junção de Nafion e um eletrodo de platina foram imersos em um recipiente de plástico contendo o eletrólito situando-se a uma distância de $2 \mathrm{~cm}$ da entrada do capilar. A outra extremidade do eletrodo foi conectada a um relê. Na base desse recipiente, havia um orifício por onde o capilar foi introduzido na cela de entrada cônica do sistema descrito anteriormente ${ }^{19}$. $\mathrm{O}$ orifício foi selado com a cola à base de epóxido e com silicone. Quando a alíquota da solução da amostra alcançava a cela cônica, o eletrodo do recipiente que continha a junção de Nafion era automaticamente conectado à fonte de alta voltagem. Assim, o fluxo eletroosmótico gerado pela ddp aplicada entre a fratura do capilar e a sua saída fazia com que uma alíquota da amostra fosse aspirada através da entrada do capilar. Com essa configuração, os efeitos discriminatórios devido à eletromigração dos analitos foram eliminados, pois, o campo elétrico era praticamente nulo na interface. Depois que a alíquota da amostra passava pela interface, a ddp era aplicada entre a entrada e a saída do capilar para fazer a separação eletroforética. Este sistema foi aplicado na separação e determinação de cafeína, teobromina e teofilina em várias amostras de refrigerantes. De acordo com os autores, a injeção baseada no fluxo eletroosmótico se mostrou efetiva, livre dos efeitos discriminatórios e independente do sentido do fluxo eletroosmótico. Além disso, a não interrupção da ddp aplicada durante a introdução da amostra permitiu que várias amostras fossem analisadas seqüencialmente aumentando a freqüência analítica.

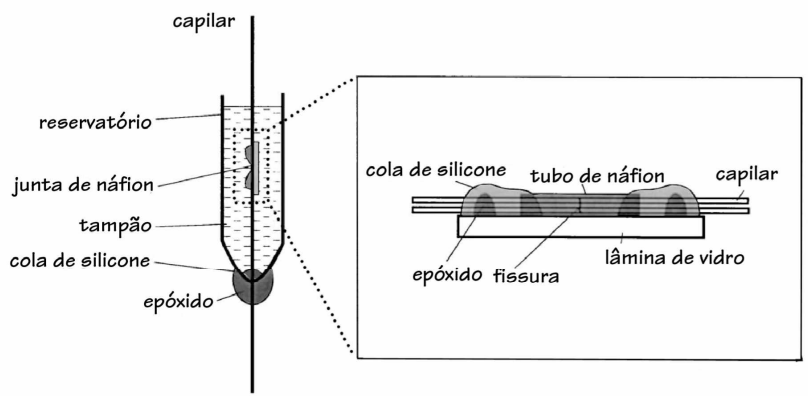

Figura 3. Representação esquemática da estrutura da junção de Nafion para efetuar injeções hidrodinâmicas, com ampliação no detalhe. Reproduzido da Anal. Chim. Acta 398; Pu, Q.-S.; Fang Z.-L.; Combination of flow injection with capillary eletrocphoresis. Part 6. A bias-free sample introduction system based on electroosmotic-flow traction; 65-74; 1999, com a permissão da Elsevier Science

\section{SISTEMAS FIA-CE ASSOCIADOS AOS MÉTODOS DE PRÉ-CONCENTRAÇÃO E SEPARAÇÃO}

\section{Diálise}

Em 1997, Kuban e Karlberg ${ }^{23}$ desenvolveram um sistema FIA$\mathrm{CE}$ associado à diálise para análise em linha de pequenos ânions. O sistema FIA-CE utilizado foi o mesmo apresentado anteriormente ${ }^{18}$. Nesse sistema, as soluções das amostras eram bombeadas até a câmara de diálise, onde os ânions atravessavam a membrana e entravam no percurso do fluxo aceptor. Este transportava os analitos até a alça de injeção. Quando a alça estava completamente preenchida, a injeção era feita e o conteúdo da alça era introduzido no percurso do eletrólito que transportava a alíquota da amostra até a interface. Ao passar pela extremidade do capilar, uma fração da amostra era eletrocineticamente introduzida no capilar, onde a separação e detecção eram feitas. Como foram feitas várias micro-injeções em uma única corrida, obteve-se uma freqüência analítica alta, comparável àquelas obtidas com os sistemas FIA convencionais. A eficiência de separação foi verificada empregando-se amostras de leite e sucos de frutas sem qualquer tratamento prévio. Segundo os autores, o arranjo FIA com diálise em linha é bastante adequado para o prétratamento de amostras com matrizes complexas antes que estas sejam introduzidas no sistema CE. O sistema resultante permitiu que fossem analisadas amostras ambientais, alimentícias e industriais contendo uma variada gama de constituintes sem qualquer tratamento prévio.

\section{Pré-concentração}

Como meio de compensar a baixa sensibilidade da CE, Chen e Fang ${ }^{20}$ desenvolveram um sistema FIA-CE com pré-concentração em linha empregando uma coluna preenchida com $\mathrm{C}_{18}$, a qual foi conectada a uma válvula de injeção de múltiplos canais. Na primeira etapa do procedimento, com a válvula na posição de injeção, a solução transportadora, que também era o eletrólito, conduzia uma alíquota de amostra concentrada no ciclo analítico anterior até a interface com divisão de fluxo, onde uma fração da amostra era eletrocineticamente introduzida no capilar, sendo o excesso, descartado. Na segunda etapa, a válvula voltava à posição de amostragem, o eluente $(40 \%$ de acetato de sódio/ácido acético $+60 \%$ de acetonitrila) passava pela coluna para eliminar qualquer resíduo da amostra do ciclo analítico anterior e a solução da amostra era trocada pela seguinte. Na terceira etapa, a válvula voltava à posição de injeção e uma nova alíquota de amostra era pré-concentrada durante 90 s. Na quarta etapa, a solução eluente dessorvia os analitos e conduzia a alíquota mais concentrada até a alça de amostragem, cujo conteúdo era transportado até a interface no ciclo analítico seguinte. Nesse sistema, o aumento de sensibilidade foi obtido pelo aumento da eficiência na transferência de fase e pelos efeitos eletroforéticos causados pela modificação da matriz da amostra durante a etapa de eluição. Com esse método, foi possível alcançar uma freqüência analítica de $9 \mathrm{~h}^{-1}$ incluindo as etapas de pré-concentração e a separação eletroforética. De acordo com os autores, ocorreu um aumento de 60 vezes na sensibilidade, com 90 s de pré-concentração, e de 180 vezes, com 240 s de pré-concentração.

Um sistema de FIA-CE foi proposto por Arce et al. ${ }^{24}$, em 1997, para a determinação de cátions e ânions. Para a determinação de alguns cátions, como $\mathrm{Mn}^{2+}, \mathrm{Al}^{3+}, \mathrm{Pb}^{2+}$ e $\mathrm{Cd}^{2+}$, foi necessário incluir uma etapa com pré-concentração. Nesse trabalho, o sistema FIA foi acoplado a um equipamento comercial de CE empregando-se um braço mecânico programável para automatização das etapas preliminares, como filtração, amostragem e pré-concentração e para a introdução das alíquotas das amostras no amostrador automático do equipamento de CE. Durante o procedimento, uma válvula seletora controlava a injeção seqüencial de amostras de água que passavam continuamente por mini-filtros antes de serem introduzidas no módulo de análise. Na etapa de pré-concentração, a válvula de amostragem era acionada e as soluções das amostras passavam pela coluna que continha a resina para retenção dos analitos. Nessa mesma etapa, era 
feita a separação e detecção do analitos que não necessitavam de pré-concentração no equipamento de CE. Quando a etapa de préconcentração era encerrada, um pequeno volume de uma solução de ácido nítrico era injetado no percurso analítico para eluir os íons retidos na coluna. A fração contendo o eluato era transportada até os reservatórios do amostrador automático pelo acionamento do braço mecânico. Os autores ressaltaram que o sistema proposto permitiu a automatização do transporte das amostras e a simplificação do processo de pré-tratamento das amostras. A aplicabilidade dessa configuração foi demonstrada pelo controle contínuo de qualidade das amostras de uma estação de purificação de água. Embora esse sistema seja automático e suas operações sejam realizadas em linha, o mesmo não apresenta uma interface FIA-CE como aquelas descritas anteriormente ${ }^{18-21}$. Nesse sistema, as alíquotas das amostras procedentes do sistema FIA eram introduzidas nos reservatórios do amostrador automático do equipamento comercial de eletroforese capilar empregando-se o braço mecânico, o qual atuava como interface entre os dois sistemas.

Arce et al. ${ }^{25}$ propuseram também um sistema FIA-CE com préconcentração em linha, utilizando a interface desenvolvida por Kuban et al. ${ }^{18}$, para determinação de nitrito, nitrato, brometo e iodeto empregando detecção UV. Nesse sistema, a coluna foi montada sobre uma válvula de seis vias. Quando essa válvula estava na posição de amostragem, a solução contendo os analitos passava através da coluna onde estes eram retidos. Na posição alternativa, o eletrólito transportava um determinado volume da solução eluente de cloreto de sódio para promover a dessorção dos analitos e conduzi-los até a interface, onde uma fração do eluato era introduzida no capilar por eletromigração. Os ânions eram, então, separados e, subseqüentemente, detectados. Com esse sistema, foi possível obter fatores de enriquecimento da ordem de 5 vezes e um desvio padrão relativo da ordem de $5 \%$.

Um sistema de injeção em fluxo acoplado a um equipamento comercial de eletroforese capilar para a separação de anilina, ácido benzóico e tirosina foi proposto por Assunção ${ }^{26}$. Uma interface semelhante àquela proposta por Kuban et al. ${ }^{18}$ foi desenvolvida para integrar os sistemas FIA e CE. Os resultados obtidos revelaram que houve perda de sensibilidade ao comparar o sistema FIA-CE com o sistema CE convencional. Entretanto, com esse sistema, foi possível fazer várias injeções seqüenciais sem necessidade de interromper a diferença de potencial aplicada, o que permitiu um aumento da freqüência analítica. Para compensar a perda de sensibilidade e melhorar a eficiência do sistema FIA-CE, uma coluna com fase sólida foi incluída no módulo de análise para pré-concentração dos analitos. Essa abordagem possibilitou um aumento de sensibilidade sem que houvesse perda de resolução dos picos.

\section{Difusão gasosa}

Um sistema FIA-CE com difusão gasosa em linha foi proposto por Kuban e Karlberg ${ }^{27}$, em 1998, para separação de analitos voláteis em amostras complexas. A interface FIA-CE foi a mesma utilizada em trabalhos anteriores ${ }^{18,23}$ mas, com uma pequena modificação. Esta consistiu em curvar a ponta do eletrodo de platina para que formasse um ângulo de $45^{\circ}$ em relação ao fluxo transportador. As condições químicas foram definidas de tal forma que os analitos fossem transformados em suas formas gasosas, as quais poderiam, subseqüentemente, atravessar a membrana de PTFE. Ao entrarem em contato com a solução aceptora, os analitos gasosos eram convertidos de volta às suas respectivas formas iônicas e eram transportados até a alça de amostragem. Quando esta era completamente preenchida, o injetor passava à posição de injeção e um volume de $50 \mu \mathrm{L}$ da solução da amostra era injetado no percurso analítico e conduzido, pelo eletrólito, até a interface. Ao passar pela extremidade do capilar, uma fração da solução da amostra era eletrocineticamente introduzida em seu interior. As múltiplas injeções de alíquotas da solução da amostra em uma mesma corrida garantiram uma freqüência analítica de $15 \mathrm{~h}^{-1}$ e foi obtido um desvio padrão relativo na faixa de 1,8-3,6\%. Para avaliar o desempenho do sistema, várias bebidas foram analisadas para determinação de espécies voláteis $\left(\mathrm{SO}_{2}\right.$ e $\left.\mathrm{CO}_{2}\right)$ e para a determinação de ânions que não formam espécies voláteis $\left(\mathrm{HCO}_{3}^{-}, \mathrm{SO}_{3}^{2-}\right.$ e acetato) sem qualquer tratamento prévio.

\section{SISTEMAS FIA-CE AUTOMATIZADOS, MINIATURIZADOS E BASEADOS EM MICROCHIPS}

A miniaturização de sistemas é uma das principais tendências na área de instrumentação, uma vez que confere aos sistemas características como: baixo consumo de amostras e reagentes, alta eficiência de separação e capacidade de detectar quantidades absolutas extremamente pequenas. Nesse contexto, a eletroforese capilar talvez seja o melhor exemplo de método em micro-escala. O desenvolvimento de métodos eletroforéticos que empregavam capilares com diâmetro interno $<100 \mu \mathrm{m}$ melhorou bastante a eficiência da técnica em termos de separação. Na década de 90 , foram propostos os primeiros sistemas de eletroforese baseados em chips, fabricados em escala normal ou micro-escala. Estes dispositivos melhoraram ainda mais a eficiência dos sistemas $\mathrm{CE}^{28-30}$.

A miniaturização dos sistemas FIA foi proposta no começo dos anos 80 por Ruzicka e Hansen ${ }^{31}$, os quais relataram o desenvolvimento de reatores que eram micro-canais construídos sobre um microsubstrato e apresentaram as instruções para miniaturização dos sistemas FIA convencionais. No artigo, os autores salientaram que ainda seria necessário o desenvolvimento de vários dispositivos instrumentais para que os micro-canais pudessem ser utilizados em larga escala na análise de rotina ${ }^{8}$. De fato, embora a proposta de miniaturização dos sistemas FIA tenha ocorrido antes daquela dos sistemas CE, a primeira não ocorreu nas mesmas proporções da segunda até o começo dos anos noventa ${ }^{32}$.

Um sistema de eletroforese capilar baseado em microchip e associado a um sistema FIA foi construído por Fu e Fang ${ }^{33}$ a partir de materiais usualmente disponíveis em laboratórios de Química Analítica. O desempenho desse sistema foi avaliado mediante a separação de glicose e sacarose empregando-se a detecção amperométrica. Na Figura 4, é apresentado o diagrama esquemático do microchip FIA-CE. O microchip foi construído sobre uma placa de vidro $(20 \mathrm{~mm} \times 70 \mathrm{~mm} \times 1 \mathrm{~mm})$ e um capilar de sílica de $5 \mathrm{~cm}$ de comprimento ( $25 \mu \mathrm{m}$ d.i. e $375 \mu \mathrm{m}$ d.e.) foi utilizado para a separação dos analitos. Cada uma de suas extremidades foi introduzida $0,8 \mathrm{~mm}$ em um tubo de Tygon ${ }^{\circledR}$ de $12 \mathrm{~mm}$ de comprimento $(1,5 \mathrm{~mm}$ d.i. e 2,5 $\mathrm{mm}$ d.e.). Os tubos de Tygon foram dispostos perpendicularmente em relação ao capilar. O tubo de Tygon da esquerda foi utilizado como interface para acoplar o sistema FIA ao sistema CE e como o compartimento do ânodo. No topo desse tubo, foi inserida a ponta de uma pipeta Eppendorf, a qual funcionava como via de entrada, enquanto, a saída foi conectada a uma bomba que aspirava o excesso de solução. Do lado oposto do capilar foi introduzido um eletrodo de platina para fechar o circuito elétrico. O tubo direito funcionava como a cela de deteção amperométrica e como compartimento do cátodo. No interior desse tubo, foram dispostos um eletrodo de trabalho de cobre, um eletrodo de referência e dois eletrodos de platina, um servia como eletrodo auxiliar e o outro, para aterrar a fonte de alta voltagem. O sistema FIA utilizado foi similar àqueles utilizados em trabalhos anteriores ${ }^{19,22}$.

Ainda em 1999, Fang et al. ${ }^{34}$ desenvolveram um outro sistema baseado em microchip, similar àquele descrito anteriormente ${ }^{33}$. Para 


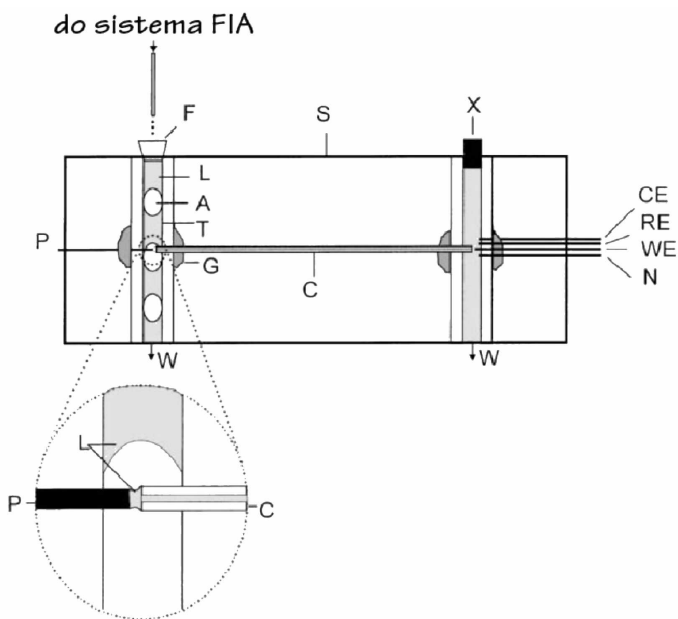

Figura 4. Diagrama esquemático da interface FIA-CE em microchip com detecção amperométrica. $C$ - coluna capilar, $S$ - base planar de vidro, $G$ epóxido, $F$-entrada cônica, $L$-fase líquida, $X$-tampa de vidro, $A$ - bolha de ar, $T$ - tubo de Tygon, $P$ - ânodo de platina, $N$ - cátodo de platina, $R E-$ eletrodo de referência, $C E$ - eletrodo auxiliar, WE - eletrodo de trabalho, W- descarte. Reproduzido da Anal. Chim. Acta 422; Fu, C.G.; Fang, Z.L.; Combination of flow injection with capillary electrophoresis Part 7. Microchip capillary electrophoresis system with flow injection sample introduction and amperometric detection; 71-79; 2000, com a permissão da Elsevier Science

minimizar o volume de amostra injetado, a injeção da amostra foi feita empregando-se um sistema de injeção seqüencial (SI) de microvolumes. Um arranjo com configuração $H$ foi adotado para permitir que a interface com divisão de fluxo (split-flow) coubesse em uma lâmina de vidro com $20 \times 70 \times 1 \mathrm{~mm}$. Nesse sistema, empregou-se um capilar de $60 \mathrm{~mm}$ comprimento ( $25 \mathrm{~mm}$ de separação efetiva) obteve-se um freqüência analítica de $40-60 \mathrm{~h}^{-1}$.

Kuban e Karlberg ${ }^{35}$ desenvolveram um sistema FIA-CE empregando bombas peristálticas programáveis em vez de válvulas para implementar injeções reprodutíveis de alíquotas de amostras. As alíquotas eram transportadas por uma solução eletrolítica até a interface, onde o capilar era inserido. Ao alcançar a interface, uma pequena fração da amostra era eletrocineticamente introduzida no capilar, uma vez que a fonte de alta voltagem permanecia ligada durante todo o processo. A eficiência do sistema foi avaliada mediante o monitoramento em linha de ânions presentes em resíduos da produção de papel. Cada ciclo analítico durava 6 min e era completamente automatizado. O sistema também foi empregado para monitorar a velocidade de oxidação em termos de mudanças na concentrações de sulfeto, sulfito e tiossulfato.

\section{APLICAÇÕES}

O sistema desenvolvido por Fang et al. ${ }^{19}$ foi utilizado na separação quiral de enantiômeros na síntese de cloranfenicol ${ }^{36}$. A $\beta$ ciclodextrina e seus derivados, utilizados como seletores quirais, foram adicionados ao eletrólito, o qual funcionou também como solução transportadora no sistema FIA. A resolução na linha base dos enantiômeros 2-amino-1-( $p$-nitrofenil-1,3-propanediol) alcançada empregando o sistema FIA-CE demonstrou que esse sistema superou o sistema $\mathrm{CE}$ convencional com respeito à precisão das medidas e à freqüência analítica. Como desvantagem, foi apontado o alto consumo de reagente, o qual, segundo os autores, poderia ser minimizado pela alteração da configuração da interface. Obteve-se uma frequiên- cia analítica de $15 \mathrm{~h}^{-1}$, o que representa uma frequiência 5 vezes maior que a da CE convencional. Essa frequiência analítica foi atribuída à não interrupção da ddp aplicada durante a análise.

Chen e Fang ${ }^{37}$, considerando a alta freqüência analítica obtida nos sistemas FIA-CE, implementaram um sistema para monitoramento da dissolução de multi-componentes de drogas. O sistema FIA-CE foi o mesmo utilizado em outros trabalhos dessa série ${ }^{19,20,36}$. Dois componentes ativos de tabletes de sulfatrim, trimetoprim e sulfametoxazol foram dissolvidos em $0,1 \mathrm{~mol} \mathrm{~L}^{-1}$ de ácido clorídrico e foram introduzidos eletrocineticamente em um capilar de $14,5 \mathrm{~cm}$ de comprimento efetivo. Para melhorar a resolução do processo de dissolução, a frequiência analítica foi aumentada em duas vezes mediante a sobreposição parcial das zonas amostrais vizinhas. Obtevese uma frequiência analítica de $60 \mathrm{~h}^{-1}$ quando a dissolução foi feita em um único frasco e $48 \mathrm{~h}^{-1}$ (24 duplicatas) quando feita em dois frascos. Os autores ressaltaram que as informações obtidas empregando o sistema FIA-CE no processo de dissolução podem ser muito úteis no desenvolvimento de novas drogas e no controle de qualidade de fármacos. Os resultados obtidos utilizando essa metodologia foram comparados àqueles obtidos em cromatografia líquida e apresentaram boa concordância entre si.

Kuban et al. ${ }^{38}$ propuseram um método para determinação de pequenos cátions inorgânicos em amostras contendo grandes quantidades de proteínas, como leite e plasma. Para implementar esse procedimento, foi utilizado um sistema FIA-CE similar àquele empregado em trabalhos anteriore ${ }^{18,21}$. As amostras foram apenas diluídas antes da análise e nenhum outro tipo de pré-tratamento foi utilizado. De acordo com os autores, a injeção eletrocinética associada à composição do eletrólito melhorou de forma significativa a repetibilidade do tempo de migração dos analitos devido à injeção discriminatória e menor adsorção de proteínas nas parede do capilar.

Um método para determinação de pseudoefedrinas em amostras de plasma humano foi proposto por Chen e Fang ${ }^{39}$. Para isso foi empregado o sistema descrito anteriormente ${ }^{20}$, o qual combinava o sistema FIA-CE com um método de pré-concentração. Esse sistema foi modificado para determinação dos analitos em níveis traço para aplicação em estudos farmacocinéticos após administração oral das drogas em pacientes voluntários. Esse método alcançou uma frequiência analítica de $10 \mathrm{~h}^{-1}$ e um limite de detecção de $12 \mathrm{mg} \mathrm{L}^{-1}$.

Kuban e Karlberg ${ }^{40}$ propuseram um trabalho, no qual compararam um sistema FIA-CE utilizado em procedimentos analíticos anteriore $^{18,21,38}$ e um sistema sem a válvula de injeção da solução da amostra. Esta foi substituída por um arranjo com injeção hidrodinâmica que incluía duas bombas peristálticas programáveis. O sistema sem válvula foi utilizado para o monitoramento em linha dos principais ânions presentes em resíduos de fabricação de papel. Cada amostra foi analisada em um intervalo de tempo de 6 min de uma forma completamente automatizada. Os autores salientaram que o desempenho analítico desse sistema foi comparável ao desempenho do sistema com válvula. O sistema desenvolvido permitiu que as velocidades de oxidação das amostras fossem monitoradas e os mecanismos de reação, avaliados. Além disso, a etapa de amostragem pode ser completamente automatizada, assim como as etapas de pré-tratamento da amostra.

Na Tabela 1, são apresentados os trabalhos que envolvem o acoplamento FIA-CE, destacando-se os analitos de interesse, a matriz da amostra considerada, o sistema de detecção e o tipo de eletrólito utilizados.

\section{PERSPECTIVAS FUTURAS}

A contínua evolução dos sistemas hibridizados FIA-CE no que se refere à sensibilidade, precisão e freqüência analítica poderá permitir que os sistemas FIA passem a ser a forma usual de introdução 
Tabela 1. Compilação dos trabalhos envolvendo o acoplamento FIA-CE

\begin{tabular}{|c|c|c|c|c|}
\hline Analitos & Matriz da Amostra & Sistema de Detecção & Eletrólito & Ref. \\
\hline $\mathrm{Cl}^{-}, \mathrm{NO}_{3}^{-}, \mathrm{NO}_{2}^{-}, \mathrm{SO}_{4}^{2-}, \mathrm{PO}_{3}^{2-}$, & Água & Arranjo de diodos & $\begin{array}{l}2 \mathrm{mM} \text { de } \mathrm{DETA}^{\mathrm{a}} \text { e } 2 \mathrm{mM} \text { de } \\
\text { dicromato }\end{array}$ & 24 \\
\hline $\begin{array}{l}\mathrm{Na}^{+}, \mathrm{K}^{+}, \mathrm{NH}_{4}^{+}, \mathrm{Ca}^{2+}, \mathrm{Mg}^{2+}, \mathrm{Fe}^{2+} \\
\mathrm{Mn}^{2+}, \mathrm{Al}^{3+}, \mathrm{Pb}^{2+} \mathrm{e} \mathrm{Cd}^{2+}\end{array}$ & & & $\begin{array}{l}\text { Mistura de } 4 \mathrm{mM} \text { de } \mathrm{CuSO}_{4}, 4 \mathrm{mM} \\
\text { de ácido fórmico e } 3 \mathrm{mM} \text { de éter } \\
\text { 18-coroa- } 6(\mathrm{pH} 4,5)\end{array}$ & 24 \\
\hline $\mathrm{Cl}^{-}, \mathrm{SO}_{4}^{2-}, \mathrm{NO}_{3}^{-}{\mathrm{e} \mathrm{HCO}_{3}^{-}}^{-}$ & $\begin{array}{l}\text { Água da chuva e } \\
\text { de torneira }\end{array}$ & Absorção UV-Vis & $\begin{array}{l}6 \mathrm{mM} \text { de cromato de sódio, } \\
3,2 \times 10^{-5} \mathrm{M} \text { de } \mathrm{CTAB}^{\mathrm{b}} \text { e } 3 \mathrm{mM} \\
\text { de ácido bórico }(\mathrm{pH} 8,0)\end{array}$ & 18 \\
\hline $\begin{array}{l}\mathrm{Cl}^{-}, \mathrm{SO}_{4}^{2-}, \mathrm{NO}_{3}^{-}, \mathrm{HCO}_{3}^{-} \text {, citrato, } \\
\text { maleato, succinato, benzoato, } \\
\text { lactato e butirato }\end{array}$ & $\begin{array}{l}\text { Água de torneira, neve, } \\
\text { leite, suco }\end{array}$ & Absorção UV-Vis & $\begin{array}{l}6 \mathrm{mM} \text { de cromato de sódio, } \\
3,2 \times 10^{-5} \mathrm{M} \text { de } \mathrm{CTAB} \text { e } 3 \mathrm{mM} \\
\text { de ácido bórico }(\mathrm{pH} 8,0)\end{array}$ & 23 \\
\hline Ácido benzóico e magnolol & Solução padrão & Absorção UV-Vis & $\begin{array}{l}25 \mathrm{mM} \text { de tetraborato de sódio } \\
\text { (pH 9,3) }\end{array}$ & 19 \\
\hline $\begin{array}{l}\text { Enantiômeros de 2-amino-1-(p- } \\
\text { nitrofenil-1,3-propanodiol) }\end{array}$ & Solução padrão & Absorção UV-Vis & $50 \mathrm{mM}$ de fosfato $(\mathrm{pH} 2,5)$ & 37 \\
\hline Pseudoefedrina & Solução padrão & Absorção UV & $50 \mathrm{mM}$ de fosfato $(\mathrm{pH} 4,0)$ & 20 \\
\hline Aminas biogênicas & Vinho & Arranjo de diodos & $\begin{array}{l}4 \mathrm{mM} \text { de sulfato de cobre, } \\
\text { ácido fórmico, e éter } \\
18 \text {-coroa- } 6(\mathrm{pH} \mathrm{4,5)}\end{array}$ & 42 \\
\hline Polifenóis & Vinho & Arranjo de diodos & $\begin{array}{l}0,1 \mathrm{M} \text { e } 0,5 \mathrm{M} \text { de hidróxido } \\
\text { de sódio }\end{array}$ & 43 \\
\hline $\mathrm{NO}_{3}^{-}, \mathrm{SO}_{4}^{2-} \mathrm{e} \mathrm{Cl}$ & Solo & Arranjo de diodos & $\begin{array}{l}2 \mathrm{mM} \text { de dicromato de potássio } \\
\text { e } 2 \mathrm{mM} \text { de DETA }(\mathrm{pH} 7,5)\end{array}$ & 44 \\
\hline Polifenóis anti-carcinogênicos & Chá & Absorção UV & 0,15 M de ácido bórico (pH 8,5) & 45 \\
\hline Trimetoprim e sulfametoxazol & Droga & Absorção UV & $75 \mathrm{mM}$ de fosfato $(\mathrm{pH} 6,5)$ & 38 \\
\hline Pseudoefedrina & Plasma humano & Absorção UV & $\begin{array}{l}200 \mathrm{mM} \text { de ácido acético-acetato } \\
\text { de sódio com } 0,1 \% \text { de } \\
\text { polietilenoglicol (pH 4,4) }\end{array}$ & 40 \\
\hline $\begin{array}{l}\text { Teofilina, ácido p-cumárico, ácido } \\
\text { caféico e ácido gálico }\end{array}$ & Solução padrão & Arranjo de diodos & 0,1 M de ácido bórico $(\mathrm{pH} \mathrm{8,0)}$ & 46 \\
\hline Ortofosfato & Solução padrão & Absorção VIS & $\begin{array}{l}10 \mathrm{mM} \text { de tetraborato de sódio } \\
(\mathrm{pH} 9,22)\end{array}$ & 47 \\
\hline $\mathrm{NO}_{3}^{-}, \mathrm{NO}_{2}^{-}, \mathrm{Br}^{-}$e I- & Solução padrão & Absorção UV & 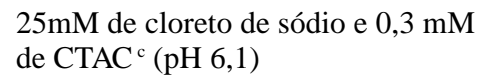 & 25 \\
\hline Cafeína, teobromina e teofilina & Café, chá, cola & Absorção UV indireta & $\begin{array}{l}30 \mathrm{mM} \text { de tetraborato de sódio } \\
(\mathrm{pH} 10)\end{array}$ & 22 \\
\hline $\mathrm{K}^{+}, \mathrm{Na}^{+}, \mathrm{Mg}^{2+} \mathrm{e} \mathrm{Ca}^{2+}$ & $\begin{array}{l}\text { Água de torneira, água } \\
\text { mineral e refrigerante }\end{array}$ & Absorção UV indireta & $\begin{array}{l}5 \mathrm{mM} \text { de aminopiridina e } 7 \times 10^{-6} \mathrm{M} \\
\text { de CTAB }(\mathrm{pH} 4,5)\end{array}$ & 21 \\
\hline $\mathrm{K}^{+}, \mathrm{Na}^{+}, \mathrm{Mg}^{2+} \mathrm{e} \mathrm{Ca}^{2+}$ & Leite, plasma & Absorção UV indireta & $\begin{array}{l}5 \mathrm{mM} \text { de p-aminopiridina e } 7 \mathrm{mM} \\
\text { de CTAB }(\mathrm{pH} 4,5)\end{array}$ & 39 \\
\hline Ácido benzóico e o-nitrofenol & Solução padrão & Absorção UV & $\begin{array}{l}30 \mathrm{mM} \text { de tetraborato de sódio } \\
(\mathrm{pH} \mathrm{10)}\end{array}$ & 48 \\
\hline Sacarose e glicose & Solução padrão & Amperometria & 0,1 M de Hidróxido de sódio & 34 \\
\hline $\begin{array}{l}\mathrm{Cl}^{-}, \mathrm{NO}_{3}^{-}, \mathrm{HS}^{-}, \mathrm{HCO}_{3}^{-}, \mathrm{SO}_{4}^{2-}, \\
\mathrm{S}_{2} \mathrm{O}_{3}^{2-}, \mathrm{SO}_{3}^{2-}, \text { formiato e oxalato }\end{array}$ & $\begin{array}{l}\text { Resíduos da indústria } \\
\text { de papel }\end{array}$ & Absorção UV indireta & $\begin{array}{l}\text { 3, } 5 \mathrm{mM} \text { de cromato e } 30 \mathrm{mM} \\
\text { de CTAB }(\mathrm{pH} 11)\end{array}$ & 41 \\
\hline
\end{tabular}

de amostras nos sistemas CE. Desse modo, os sistemas FIA-CE poderão ser utilizados, em larga escala, em análises de rotina, uma vez que processos como pré-concentração, diálise, filtração, etc., poderão ser implementados em linha.

O desempenho dos sistemas deverá ser melhorado com a miniaturização e o emprego de sistemas integrados com microchips.

\footnotetext{
a Do inglês: diethylene triamine

${ }^{\mathrm{b}}$ Do inglês: cetyltrimethylammonium bromide

${ }^{\mathrm{c}}$ Do inglês: cetyltrimethylammonium chloride

${ }^{d}$ Do inglês: inductively coupled plasma mass spectrometry
}

Isso permitirá o desenvolvimento de sistemas portáteis que poderão ser utilizados em monitoramentos ambientais e biológicos in loco.

Além dos detectores UV-Vis, arranjos de diodos e amperométricos já utilizados nos sistema FIA-CE, outros mais sensíveis, como os espectrômetros de massas e os espectrômetros de massas com fonte de plasma (ICP-MS ${ }^{\mathrm{d}}$ ) deverão ser utilizados. Isso permitirá que analitos com concentrações aproximadas de $\mathrm{ng} \mathrm{mL}^{-1}$ possam ser separados e detectados.

Em meados dos anos noventa, foram propostos os primeiros sistemas CE-ICP-MS ${ }^{48-50}$. Desde então, assim como os sistemas FIA$\mathrm{CE}$, esses sistemas encontram-se em fase de expansão. Atualmente, 
o Laboratório de Química Analítica do Centro de Energia Nuclear (CENA/USP) e o Laboratório de Cromatografia do Instituto de Química de São Carlos (IQSC/USP) estão desenvolvendo em conjunto um sistema FIA-CE-ICP-MS ${ }^{51}$ para especiação de íons inorgânicos e compostos organo-metálicos. Isso reflete a consolidação de uma tendência, na química analítica, de associar diferente técnicas e processos visando explorar as suas respectivas vantagens e, simultaneamente, compensar as suas deficiências. No caso do sistema FIA-CEICP-MS, a hibridização foi proposta com o objetivo de explorar a capacidade intrínseca de gerenciamento e pré-tratamento de soluções dos sistemas FIA, a alta capacidade de separação da eletroforese capilar e a alta sensibilidade do ICP-MS.

\section{CONCLUSÃO}

As limitações que impediam o acoplamento dos sistemas FIA com a Eletroforese Capilar, como a forma descontínua de introdução da solução da amostra, injeção discriminatória (eletrocinética) ou a baixa sensibilidade, foram, de modo geral, superadas ou, pelo menos, minimizadas. Isso pode ser comprovado diante do número de aplicações dos sistemas FIA-CE na análise de amostras ambientais, industriais e biológicas. Algumas das etapas tediosas de pré-tratamento dessas amostras foram implementadas em linha e, assim, puderam ser facilmente integradas ao sistema CE. Isso permitiu, em alguns casos, a automatização completa dos sistemas, o que aumentou as potencialidades da aplicação desses sistemas em análises de rotina e processos de controle.

Finalmente, como vantagens do acoplamento FIA-CE, é possível citar:

- Excelente repetibilidade do tempo de retenção, área e altura de pico (variações menores que $2,5 \%$ );

- Aumento da freqüência analítica devido à simplificação das operações;

- Possibilidade de injeções quase simultâneas para aumentar a frequiência analítica;

- Aumento da seletividade e sensibilidade pela inclusão dos processos de pré-concentração e separação em linha.

Embora o acoplamento FIA-CE ${ }^{18,19}$ seja relativamente novo, já foram publicadas duas revisões ${ }^{52,53}$ abordando os princípios, vantagens e aplicações dessa associação. Isso confirma as grandes potencialidades dos sistemas FIA-CE no que se refere aos muitos aspectos dessa associação que ainda deverão ser explorados e às aplicações que irão advir desses estudos.

\section{AGRADECIMENTOS}

Os autores agradecem à Fundação de Amparo à Pesquisa do Estado de São Paulo (FAPESP) pelo auxílio financeiro concedido e à Elsevier Science pela permissão para reproduzir as figuras apresentadas.

\section{REFERÊNCIAS}

1. Ruzicka, J.; Hansen, E.; Anal. Chim. Acta 1975, 78, 145.

2. Mikkers, F.E.P.; Everaerts, F.M.; Verheggen, T.P.E.M.; J. Chromatogr. 1979 $169,11$.

3. Jorgenson, J.W.; Lukacs, K.D.; Anal. Chem. 1981, 53, 1298.

4 Baker, D. R.; Capillary Electrophoresis, John Wiley \& Sons: New York, 1995.

5. Reis, B. F.; Quim. Nova 1996, 19, 51.
6. Reis, B. F.; Giné, M.F.; Kronka, E.A.M.; Quim. Nova 1989, 12, 82.

7. Valcárcel, M.; Castro, M. D. L. de; Flow Injection Analysis, Principles and Aplications, Ellis Horwood: Chichester, 1987.

8. Ruzicka, J.; Hansen, E. H.; Flow Injection Analysis, Wiley: New York, $2^{\text {nd }}$ ed., 1988.

9. Karlberg, B.; Pacey, G. F.; Flow Injection Analysis: A Practical Guide, Elsevier: Amsterdam, 1989.

10. Tyson, J. F.; Microchem. J. 1992, 45, 143.

11. Burguera, J. L.; Burguera, M.; J. Anal. At. Spectrom. 1995, 10, 473.

12. Bergamin Fo, H.; Reis, B. F.; Zagatto, E. A. G.; Anal. Chim. Acta 1978, 97, 427.

13. Bergamin Fo, H.; Zagatto E. A. G.; Krug, F. J.; Reis, B. F.; Anal. Chim. Acta 1978, 101, 17.

14. Zagatto, E. A. G.; Jacintho, A. O.; Mortatti, J.; Bergamin Fo, H.; Anal. Chim. Acta 1980, 120, 399

15. Reis, B. F.; Jacintho, A. O.; Mortatti. J.; Krug, F. J.; Zagatto, E. A. G.; Bergamin Fo, H.; Pessenda, L. C. R.; Anal. Chim. Acta 1981, 123, 221.

16. Tavares, M.F.M.; Quim. Nova 1996, 19, 173.

17. Kuhn, R.; Hoffstetter-Kuhn, S.; Capillary Electrophoresis: Principles and Practice, Springer-Verlag: Berlin, 1993.

18. Kuban, P.; Engstrom, A.; Olsson, J.C.; Thorsen, G.; Tryzell, R.; Karlberg, B.; Anal. Chim. Acta 1997, 337, 117.

19. Fang, Z.-L.; Liu, Z.-S.; Shen, Q.; Anal. Chim. Acta 1997, 346, 135.

20. Chen, H.W.; Fang, Z.L.; Anal. Chim. Acta 1997, 355, 135.

21. Kuban, P.; Pirmohammadi, R.; Karlberg, B.; Anal. Chim. Acta 1999, 378, 55.

22. Pu, Q.-S.; Fang Z.-L.; Anal. Chim. Acta 1999, 398, 65.

23. Kuban P.; Karlberg, B.; Anal. Chem. 1997, 69, 1169.

24. Arce, L.; Rios, A.; Valcarcel, M.; J. Chromatogr., A 1997, 791, 279.

25. Arce, L.; Kuban, P.; Rios, A.; Valcarcel, M., Karlberg, B.; Anal. Chim. Acta 1999, 390, 39.

26. Assunção, N. A.; Dissertação de Mestrado; IQSC/USP, São Carlos, SP, 2000.

27. Kuban P.; Karlberg B.; Talanta 1998, 45, 477.

28. Manz, A.; Harrison, D.J.; Verpoorte, E.; Widmer, H.M.; Adv. Chromatogr. 1993, 33, 1 .

29. Harrison, D.J.; Manz, A.; Fan, Z.; Lüdi, H.; Widmer, H.M.; Anal. Chem. 1992, 64, 1926.

30. Hadd, A.G.; Raymond, D.E.; Halliwell, J.W.; Jacobson, S.C.; Ramsey, J.M.; Anal. Chem. 1997, 69, 3407.

31. Ruzicka, J.; Hansen, E.; Anal. Chim. Acta 1984, 161, 1.

32. Liu, S.; Dasgupta, P.K.; Anal. Chim. Acta 1992, 268, 1.

33. Fu, C.G.; Fang, Z.L.; Anal. Chim. Acta 2000, 422, 71.

34. Fang, Q.; Wang, F.-R.; Wang, S.-L.; Liu, S.-S.; Xu, S.-K.; Fang, Z.-L.; Anal. Chim. Acta 1999, 390, 27.

35. Kuban P.; Karlberg, B.; Anal. Chim. Acta, 2000, 404, 19.

36. Liu, Z.S.; Fang, Z.L.; Anal. Chim. Acta 1997, 353, 199.

37. Chen, H.W.; Fang, Z.L.; Anal. Chim. Acta 1998, 376, 209.

38. Kuban, P.; Oldhoff, O.; Karlberg, B.; J. Chromatogr., A 1999, 857, 321.

39. Chen, H.W.; Fang, Z.L.; Anal. Chim. Acta 1999, 394, 13

40. Kuban, P.; Karlberg, B.; Anal. Chim. Acta 2000, 404, 19.

41. Arce, L.; Ríos, A.; Valcárcel, M.; J. Chromatogr. 1998, 803, 249.

42. Arce, L.; Ríos A., Tena, M. T.; Valcárcel, M., J.; Anal. Chim. Acta 1998, 359, 27.

43. Arce, L.; Ríos, A.; Valcárcel, M. J.; Fresenius J. Anal. Chem. 1998, 360, 697.

44. Arce, L.; Ríos, A.; Valcárcel, M., J.; J. Chromatogr. A 1998, 827, 113.

45. Arce, L.; Hinsmann, P.; Novic, M.; Ríos, A.; Valcárcel, M.; Electrophoresis 2000, 21(3), 556.

46. Doku, G.N.; Haswell, S.J.; Anal. Chim. Acta 1999, 382(1-2), 1.

47. Tuma P.; Opekar, F.; Jelínek, I.; J. Chromatogr. A, 2000, 883, 223.

48. Liu, Y.; Avila-Lopez, V.; Zhu, J. J.; Wiederin, D. R.; Beckert, W. F.; Anal. Chem. 1995, 67, 2020.

49. Olesik, J. W.; Kinzer, J. A.; Olesik, S.V.; Anal. Chem. 1995, 67, 1.

50. Lu, Q.; Barnes, R. M.; Microchem. J. 1996, 54, 126.

51. Giné, M.F.; Gervasio, A.P.G.; Miranda, C.E.S.; Lavorante, A.F.; Reis, B.F.; Carrilho, E.; Winter Conference on Plasma Spectrochemistry, Scottsdale, USA, 2002.

52. Kuban P.; Karlberg, B.; Trends in Anal. Chem. 1998, 17, 34.

53. Fang Z.-L.; Chen, H.-W.; Fang, Q.; Pu, Q.-S., Anal. Sciences 2000, 16, 197. 